\title{
AS PESQUISAS SOBRE A LITERATURA NA EDUCAÇÃO INFANTIL A PARTIR DO PROJETO POLÍTICO-PEDAGÓGICO
}

\author{
Simoni Conceição Claudino \\ Prefeitura Municipal de Florianópolis \\ Universidade Federal de Santa Catarina - UFSC \\ Diana Carvalho de Carvalho \\ Universidade Federal de Santa Catarina - UFSC \\ Eliane Santana Dias Debus \\ Universidade Federal de Santa Catarina - UFSC
}

\begin{abstract}
Resumo
$\mathrm{O}$ artigo apresenta um estado do conhecimento que mapeou pesquisas brasileiras sobre literatura na Educação Infantil, em particular a partir dos projetos Político-Pedagógicos (PPPs) buscando compreender como o ensino de literatura nessa etapa da Educação Básica tem sido tratado e discutido, para isso realizamos levantamento em três bancos de dados: a) teses e dissertações disponibilizadas na Biblioteca Digital Brasileira de Teses e Dissertações (BDTD), nos anos de 1978 a 2015; b) artigos e publicações disponibilizados no Portal de Periódicos da Coordenação de Aperfeiçoamento de Pessoal de Nível Superior (Capes) no período de 1998 a 2016, período disponível pela plataforma e; c) artigos publicados e disponibilizados no Scientific Eletronic Library Online (SciELO), no período de 1998 a 2016. Considerando os descritores associados Educação Infantil, Literatura Infantil e Projeto Político-pedagógico, constatamos que a relação entre a Literatura Infantil, a Educação Infantil e o PPP não está no foco das pesquisas. Escreve-se e pesquisa-se sobre a Educação Infantil, sobre a Literatura Infantil, sobre a Literatura na Educação Infantil, mas não sobre a ação e o registro desse trabalho nos documentos norteadores da ação educativa das instituições, ou seja, não há atenção à presença da Literatura nos PPPs das instituições de Educação Infantil.
\end{abstract}

Palavras-chave: Estado do conhecimento; Literatura; Educação infantil.

\begin{abstract}
The article presents a state of knowledge that has mapped Brazilian research on Literature in Child Education, in particular from the Pedagogical Political Projects (PPPs), seeking to understand how the teaching of literature in this stage of Basic Education has been treated and discussed. in three databases: a) theses and dissertations available in the Brazilian Digital Library of Theses and Dissertations (BDTD), from 1978 to 2015; b) articles and publications made available in the Portal of Periodicals of the Coordination for the Improvement of Higher Education Personnel (Capes) from 1998 to 2016, period available by the platform; c) articles published and available in the Scientific Electronic Library Online (SciELO), from 1998 to 2016. Considering the descriptors associated with Early Childhood Education, Child Literature and Political Pedagogical Project, we found that the relationship between Children's Literature, PPP is not in the research focus. We write and research on Child Education, on Children's Literature, on Literature in Early Childhood Education, but not on the action and registration of this work in the documents guiding the educational action of the institutions, that is, there is no attention to the presence of Literature in the PPPs of the institutions of Early Childhood Education.
\end{abstract}

Keywords: State of knowledge; Literature; Child education. 


\section{Introdução}

Em pesquisa que tomou por referência o Projeto Político-Pedagógico (PPP) como documento norteador das ações educativas das unidades de Educação Infantil de uma rede municipal de Santa Catarina, buscamos a presença de diferentes discursos acerca da leitura literária que pontuavam a identidade, autonomia e as práticas pedagógicas coletivas registradas. Utilizou-se como referencial teórico os estudos da Teoria Histórico-Cultural, que tem em Vigotski seu principal representante, bem como os estudos acerca da teoria de recepção literária, especialmente referentes à leitura literária e à primeira infância. Entendemos o PPP como documento norteador das ações educativas das unidades e que deve representar a participação coletiva dos profissionais na sua elaboração e execução.

Ao definir os caminhos da investigação foi de fundamental importância a realização de um estado do conhecimento, para identificar como a produção acadêmica tratava a temática em questão. Desse modo, este artigo busca apresentar estado do conhecimento que mapeou pesquisas brasileiras que versam sobre literatura na Educação, em particular no espaço da Educação Infantil, buscando compreender como o ensino de literatura nessa etapa da Educação Básica tem sido tratado e discutido, a partir da elaboração e escrita coletiva dos Projetos Político-Pedagógicos. Para isso utilizamos três descritores associados ao tema: Projeto Político-Pedagógico, Literatura Infantil e Educação Infantil. Os descritores foram utilizados de modo separado e associados, em três bancos de dados eletrônicos, com informações científicas e que permitem o acesso integral às pesquisas: a) teses e dissertações disponibilizadas na Biblioteca Digital Brasileira de Teses e Dissertações (BDTD), que é concebida e mantida pelo Instituto Brasileiro de Informação em Ciência e Tecnologia (IBICT); b) artigos e publicações disponibilizados no Portal de Periódicos da Coordenação de Aperfeiçoamento de Pessoal de Nível Superior (Capes); c) artigos publicados e disponibilizados no Scientific Eletronic Library Online (SciELO).

Vale, nesse momento, esclarecer que o banco de teses e dissertações da Capes, encontrava-se em manutenção durante o período em que o estado do conhecimento fora realizado, e disponibilizava a pesquisa apenas teses e dissertações defendidas nos anos de 2011 e 2012, o que não nos era suficiente, assim a opção foi recorrer ao banco de teses e dissertações da BDTD para que conseguíssemos acessar um número maior de teses e dissertações, de modo mais eficiente à pesquisa. Desse modo, o período de investigação nestes bancos de dados deu-se no período circunscrito aos anos de 1978 a 2016.

A pesquisa geral realizada nos três bancos de dados selecionados forneceu os seguintes números expostos no Quadro 1, a seguir. 
Quadro 1 - Trabalhos disponibilizados nas bases de dados, conforme os descritores: Projeto Político-Pedagógico, Literatura Infantil e Educação Infantil

\begin{tabular}{|l|r|r|r|}
\hline \multicolumn{1}{|c|}{ Base de dados } & \multicolumn{3}{c|}{ Descritor utilizado } \\
\hline & Educação Infantil & Literatura Infantil & Projeto Político-Pedagógico \\
\hline BDTD & 3642 & 1284 & 1329 \\
\hline Periódicos Capes & 1842 & 1798 & 282 \\
\hline SciELO & 1050 & 657 & 137 \\
\hline Total & 6484 & 3739 & 1748 \\
\hline
\end{tabular}

Fonte: Elaborado pelas pesquisadoras.

Em virtude da grande quantidade de trabalhos relacionados às temáticas apresentadas separadamente, realizamos a pesquisa nos mesmos bancos de dados, porém com os descritores utilizados de forma associada. Dessa forma, houve uma redução no número de trabalhos e uma possível aproximação da temática que buscávamos nesse levantamento. Trabalhamos, assim, nos três bancos de dados com os descritores associados. Os números de trabalhos referentes à pesquisa com os descritores associados estão expostos no Quadro 2.

Quadro 2 - Trabalhos disponibilizados nas bases de dados, conforme os descritores associados: Projeto Político-Pedagógico, Literatura Infantil e Educação Infantil

\begin{tabular}{|l|r|r|r|r|}
\hline \multirow{2}{*}{ Base de dados } & \multicolumn{4}{|c|}{ Descritores associados } \\
\cline { 2 - 6 } & $\begin{array}{c}\text { Literatura } \\
\text { Infantil }+ \\
\text { Educação } \\
\text { Infantil }\end{array}$ & $\begin{array}{c}\text { Literatura Infantil } \\
\text { + Projeto Político- } \\
\text { Pedagógico }\end{array}$ & $\begin{array}{c}\text { Educação } \\
\text { Infantil + } \\
\text { Projeto Político- } \\
\text { Pedagógico }\end{array}$ & $\begin{array}{c}\text { Literatura Infantil } \\
\text { + Educação Infantil } \\
\text { + Projeto Político- } \\
\text { Pedagógico }\end{array}$ \\
\hline BDTD & 461 & 8 & 90 & 5 \\
\hline Periódicos Capes & 193 & 83 & 8 & 82 \\
\hline SciELO & 98 & - & 4 & 82 \\
\hline Total & 752 & 91 & & \\
\hline
\end{tabular}

Fonte: Elaborado pelas pesquisadoras.

Realizado o levantamento geral sobre a temática, apresentamos o resultado encontrado nas bases de dados escolhidas, considerando os descritores associados, e descrevemos como foi o processo de seleção dos trabalhos que dialogam com a presente investigação.

\section{A pesquisa na Biblioteca Digital Brasileira de Teses e Dissertações - BDTD}

A Biblioteca Digital Brasileira de Teses e Dissertações (BDTD) disponibiliza online metadados relacionados às teses e dissertações defendidas no país, tais como: título, autor, 
resumo, palavras-chave, orientador, ano, grau, instituição. Essa base permite ao pesquisador uma ordenação por data (ascendente e descendente), título, autor (ordem alfabética) e relevância, embora não fique evidenciado qual o critério definidor da relevância. Depois de selecionado, o documento na íntegra deve ser consultado na página da instituição de origem, podendo ser impresso ou feito o download do arquivo.

A pesquisa no banco de dados com a utilização dos descritores associados Literatura Infantil e Educação Infantil permitiu a identificação de trabalhos defendidos entre os períodos de 1978 a 2016. Os trabalhos selecionados para leitura completa e análise estão todos circunscritos entre os anos de 2007 a 2016. A ênfase nesta data, em nosso entendimento, deve-se à indicação de que a Literatura Infantil vem mantendo vínculos com a Educação Infantil mesmo antes das legislações nacionais mais definidoras do caráter educativo dessas instituições e das políticas de distribuição do livro infantil em nosso país.

No Quadro 3, que segue, apresentamos a quantidade de trabalhos encontrados com os descritores associados Literatura Infantil e Educação Infantil.

Quadro 3 - Trabalhos encontrados na BDTD com os descritores associados Literatura Infantil e Educação Infantil

\begin{tabular}{|c|c|c|c|}
\hline & Total & Dissertações & Teses \\
\hline Quantidade de trabalhos & 461 & 357 & 104 \\
\hline Trabalhos filtrados por assuntos & 165 & 126 & 39 \\
\hline
\end{tabular}

Fonte: Elaborado pelas pesquisadoras.

Com os descritores Literatura Infantil e Educação Infantil foram encontrados 461 trabalhos. Ao aplicarmos o filtro "assunto", disponibilizado na plataforma, foram selecionados 165 trabalhos, a saber: 64 em Educação, 62 em Educação Infantil, e 39 em Literatura Infantil. Alguns trabalhos se repetiam, pois os mesmos são categorizados em mais de um assunto.

Realizada a leitura inicial dos títulos, muitas teses e dissertações foram excluídas da seleção, pois faziam análise de uma obra ou de um autor específico da Literatura Infantil; tratavam de temáticas específicas, tais como: livros didáticos, livros de imagem, poesias, inclusão, gênero e raça, sexualidade, trabalho infantil, prevenção de acidentes, educação bilíngue, mercado de brinquedos; tinham locais de pesquisa não relacionados à Educação Infantil, a saber: ambiente hospitalar, momentos de recreio, uma disciplina escolar, trabalhos de fonoaudiologia, nutrição, psicologia ou saúde pública; estavam relacionados a outras etapas da Educação Básica, como Ensino Fundamental ou Ensino Médio.

Desse modo, 19 trabalhos, entre teses e dissertações, foram selecionados para a realização da leitura dos resumos e palavras-chave, pois os títulos não definiam dados mais específicos acerca da pesquisa realizada. Lidos os resumos, verificou-se que, em sua maioria, os trabalhos tratavam de pesquisa no Ensino Fundamental. 
Dito isso, cinco dissertações foram escolhidas para leitura na íntegra por apontarem possíveis caminhos que dialogam com a presente investigação, destacando que todas foram defendidas entre os anos de 2007 a 2016, sendo quatro na área de Educação e uma na área de Psicologia. A seguir, no Quadro 4, passamos a apresentação de forma mais detalhada dos trabalhos selecionados para leitura, a partir dos descritores Literatura Infantil e Educação Infantil

Quadro 4 - Dissertações selecionadas na BDTD com os descritores Literatura Infantil e Educação Infantil

\begin{tabular}{|c|c|c|c|c|c|c|}
\hline Área & Ano & Local & Autor & Orientador & Título & Palavras-chave \\
\hline $\begin{array}{l}\frac{\pi}{60} \\
\frac{0}{0} \\
\frac{0}{n} \\
2\end{array}$ & 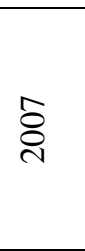 & 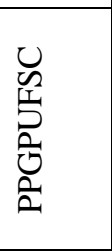 & Taís Danna & $\begin{array}{l}\text { Andréa } \\
\text { Vieira } \\
\text { Zanella }\end{array}$ & $\begin{array}{l}\text { Literatura e imaginação: } \\
\text { realidade e } \\
\text { possibilidades em um } \\
\text { contexto de educação } \\
\text { infantil. }\end{array}$ & $\begin{array}{l}\text { Literatura infantil, } \\
\text { criatividade, imaginação, } \\
\text { educação infantil, } \\
\text { produção de sentidos, } \\
\text { contação, constituição do } \\
\text { sujeito. }\end{array}$ \\
\hline 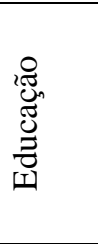 & $\stackrel{m}{\stackrel{n}{\sigma}}$ & 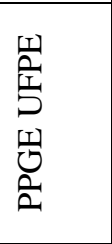 & $\begin{array}{l}\text { Cinthia Silva } \\
\text { de } \\
\text { Albuquerque }\end{array}$ & $\begin{array}{l}\text { Ana } \\
\text { Carolina } \\
\text { Perrusi } \\
\text { Alves } \\
\text { Brandão }\end{array}$ & $\begin{array}{l}\text { Os acervos, os espaços e } \\
\text { os projetos de leitura em } \\
\text { instituições públicas de } \\
\text { educação infantil do } \\
\text { Recife. }\end{array}$ & $\begin{array}{l}\text { Educação infantil, } \\
\text { formação de leitores, } \\
\text { espaços de leitura, } \\
\text { acervo de literatura } \\
\text { infantil, mediação de } \\
\text { leitura. }\end{array}$ \\
\hline 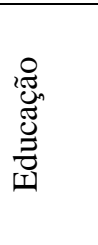 & $\stackrel{0}{\stackrel{1}{\circ}}$ & 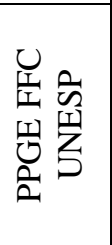 & $\begin{array}{l}\text { Lizbeth } \\
\text { Oliveira de } \\
\text { Andrade }\end{array}$ & $\begin{array}{l}\text { Cyntia } \\
\text { Graziella } \\
\text { Guizelim } \\
\text { Simões } \\
\text { Girotto }\end{array}$ & $\begin{array}{l}\text { Desenvolvimento da } \\
\text { memória em crianças } \\
\text { pré-escolares por meio } \\
\text { de atividades literárias: } \\
\text { contribuições da teoria } \\
\text { histórico-cultural. }\end{array}$ & $\begin{array}{l}\text { Educação, educação } \\
\text { infantil, memória, teoria } \\
\text { histórico-cultural, } \\
\text { atividade literária. }\end{array}$ \\
\hline 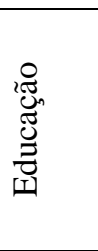 & $\stackrel{\circ}{\stackrel{0}{\circ}}$ & 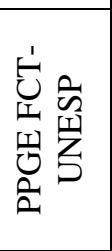 & $\begin{array}{l}\text { Thaís } \\
\text { Borella }\end{array}$ & $\begin{array}{l}\text { Irineu } \\
\text { Aliprando } \\
\text { Tuim } \\
\text { Viotto } \\
\text { Filho }\end{array}$ & $\begin{array}{l}\text { Desenvolvimento da } \\
\text { linguagem infantil à luz } \\
\text { da teoria histórico- } \\
\text { cultural: contribuições de } \\
\text { práticas literárias na } \\
\text { primeira infância. }\end{array}$ & $\begin{array}{l}\text { Educação infantil, teoria } \\
\text { histórico-cultural, } \\
\text { desenvolvimento da } \\
\text { linguagem, funções } \\
\text { psicológicas superiores, } \\
\text { literatura infantil. }\end{array}$ \\
\hline 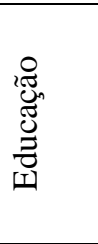 & $\stackrel{\circ}{\stackrel{0}{0}}$ & 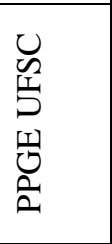 & $\begin{array}{l}\text { Thamirys } \\
\text { Frigo } \\
\text { Furtado }\end{array}$ & $\begin{array}{l}\text { Eliane } \\
\text { Santana } \\
\text { Dias Debus }\end{array}$ & $\begin{array}{l}\text { Espaços e tempos } \\
\text { coletivos de leitura } \\
\text { literária na educação } \\
\text { infantil da rede } \\
\text { municipal de } \\
\text { Florianópolis (SC) }\end{array}$ & $\begin{array}{l}\text { Espaço e tempo coletivo } \\
\text { de leitura, formação de } \\
\text { crianças-leitoras, leitura } \\
\text { literária. }\end{array}$ \\
\hline
\end{tabular}

Fonte: Elaborado pelas pesquisadoras.

Realizada a leitura das dissertações, verificamos que Danna (2007) faz sua pesquisa com crianças da pré-escola de uma escola de Jaraguá do Sul (SC), e utiliza-se de observação, gravação de vídeos e entrevistas realizadas com os professores (de sala e de educação física), com a bibliotecária e com os pais das crianças. Fundamenta-se em 
conceitos de literatura e imaginação pautados numa perspectiva histórico-cultural e procura, no decorrer de sua pesquisa, verificar se a escola é difusora e produtora da cultura e arte, a partir do acesso das crianças aos livros e da ampliação da capacidade criativa de seus muitos enredos. A autora relata diversas formas de registros no decorrer da história da humanidade e aponta a escrita como forma propícia de superação dos limites da memória. Apresenta, ainda, a dificuldade de estabelecimento de parâmetros ou padrões ao que é, ou não, Literatura Infantil, mostrando o que não é obra de leitura exclusiva de crianças, mas que é também leitura para crianças. Evidencia que na turma observada há a contação diária de histórias pela professora regente e, semanalmente, há a contação de histórias na biblioteca da escola. Ressalta que no PPP da instituição não há menção aos projetos de literatura e que, em conversa com as famílias, elas percebem a presença da literatura na escola pelos relatos dos filhos e dos pedidos por leituras feitos em casa.

Albuquerque (2013) busca identificar os espaços de leituras presentes em oito instituições de Educação Infantil da cidade do Recife, seus acervos e o acesso das crianças a estes acervos. Realiza entrevista com professoras e coordenadoras pedagógicas e observações nas instituições. Ressalta o percurso histórico do Programa Nacional do Livro Didático (PNLD) ao Programa Nacional Biblioteca da Escola (PNBE), e revela em sua pesquisa que muitos livros do acervo do PNBE estão guardados em caixas e armários, longe do acesso de crianças e também dos professores. Das oito instituições investigadas, apenas uma tinha espaço organizado para leituras, e das 26 turmas observadas/fotografadas nessas instituições, seis tinham livros ao acesso das crianças em expositores ou em estante aberta. Revelou também que não há projetos coletivos que envolvam o objeto livro e a contação de histórias às crianças, mostrando a ausência e a precariedade de bibliotecas e espaços de leitura, reforçando a necessidade de projetos que desenvolvam a mediação do professor e das crianças com o livro literário, bem como o incentivo ao acesso às obras.

Andrade (2016) realiza um estudo sobre a memória em crianças pré-escolares, apoiada nas pesquisas de Vigotski e Luria. Afirma em sua pesquisa que a literatura mobiliza a organização das funções psicológicas superiores, e que o texto literário é a possibilidade de ampliação de repertórios e de experiências às crianças. Em sua escrita, a autora apresenta o contexto histórico e político da Rússia e as proibições de circulação de muitos escritos. Destaca que a memória necessita de experiências, de conhecimentos para ser desenvolvida e ampliada. Em situações pedagógicas, a pesquisadora evidencia que há livros de literatura sobre os mais variados temas, contextos e gêneros. Entendido como um bem histórico e cultural, como arte e como mediador de experiências, o livro literário é apontado como possibilidade de desenvolver processos de criação e imaginação.

Borella (2016) realizou sua pesquisa junto a um grupo de 18 crianças entre dois e três anos, numa instituição de Educação Infantil, com o propósito de verificar se as atividades de leitura literária realizadas com as crianças contribuíam, de fato, ao desenvolvimento e apropriação da linguagem. Trazendo, em sua maioria, livros dos acervos do PNBE, portanto, livros presentes e distribuídos às instituições públicas de Educação Infantil, e pautada nos estudos de Vygotsky, a autora aponta a importância da mediação e da linguagem no desenvolvimento humano. Destaca a presença da linguagem oral e escrita, 
entendidas como conteúdo, nos Referenciais Curriculares Nacionais da Educação Infantil (RCNEI). Pontua, ainda, a pouca vivência da leitura literária observada nos locais por onde passou, uma realidade que comprova a ideia corrente de que o acesso aos livros e à leitura por adultos e crianças ainda é escasso em nosso País. A pesquisadora caracteriza o livro como uma criação cultural e trata da importância de um trabalho socialmente mediado com o livro. No decorrer de sua pesquisa, identifica os livros utilizados para leitura e os processos realizados nos 12 encontros com as crianças. Aponta características de diferentes tipos de leituras realizadas e alerta à falta de acesso aos livros e aos brinquedos pelas crianças. Sua pesquisa se encerra com a construção de um livro com as crianças, onde observa que personagens das brincadeiras e dos livros apresentados no decorrer dos encontros se misturam e compõem o enredo da história coletiva, revelando que, no processo de escuta das histórias, houve a ampliação da linguagem, do vocabulário, da comunicação, da pronúncia e do próprio gosto literário, bem como uma diversidade de mundos se encontraram noutra narrativa escrita, de autoria desse grupo.

Furtado (2016) realizou sua pesquisa em instituições de Educação Infantil da Rede Municipal de Florianópolis e, por meio de questionários respondidos por responsáveis pelas instituições, mapeou diferentes espaços e tempos de leitura em 71 instituições públicas desse município. Inicialmente, apresenta um histórico da produção de livros para as crianças, pontua diferenças entre o livro infantil e o livro de literatura infantil e expõe diferenças entre alfabetização, letramento e letramento literário. Ressalta a importância da aproximação da criança à cultura letrada, bem como o acesso das crianças aos livros e da mediação docente neste processo. Ao especificar a pesquisa propriamente dita, a autora assinala as orientações curriculares do município em questão, o qual, dentre outras propostas, sugere: a inclusão da cultura letrada no cotidiano, a organização de ambientes e materiais de leitura, o ato de contar e ouvir histórias diariamente. De posse dos questionários, destaca que: a maioria das instituições possui bibliotecas, ou espaços diferenciados de leitura coletiva; tem um profissional readaptado responsável por esses espaços; conta com acervo próprio; realiza planejamento para uso desses espaços. Porém, há uma minoria em desacordo com esses dados que precisa ser considerada para que todas as crianças atendidas tenham, de fato, acesso e direito à leitura. Os dados obtidos apontam a falta de formação aos profissionais responsáveis pelas bibliotecas e espaços coletivos das instituições. A autora questiona se os espaços nas instituições são espaços de livros ou espaços de leituras; revela, ainda, seu desejo em visitar alguns dos locais apontados na pesquisa. Finaliza sua pesquisa com um mapa do município onde localiza as instituições e os dados gerais gerados pelas mesmas.

Esses cinco trabalhos revelam dados interessantes à pesquisa, no que diz respeito ao referencial teórico, todos estão fundamentados nos estudos da Teoria Histórico-Cultural, principalmente nos estudos de Vigotski. Quanto ao acesso aos livros, as pesquisas evidenciam, em sua maioria, que, muitas vezes, não estão disponibilizados às crianças, nem aos professores, e o trabalho e acesso ao acervo é decorrente de iniciativas isoladas dos professores. O acesso ao livro literário e a leitura é apontado como fundamental ao desenvolvimento das crianças em seus aspectos de ampliação de conhecimento do mundo, 
de acervo de linguagem, de comunicação, além de ser destacado como direito das crianças em documentos nacionais. Considerando que o livro se constitui objeto mediador da cultura, seu acesso tem que ser propiciado e assegurado às crianças e a todos de modo geral.

Outro aspecto indicado pelas pesquisas é a precariedade de projetos coletivos nas instituições de Educação Infantil que incluam a leitura literária. Há destaque para as práticas de leituras literárias que ocorrem cotidianamente nas instituições educativas e que não constam em seus documentos coletivos, assim como há práticas que, apoiadas nos critérios de manutenção, preservação, cuidado, conservação, devolução dos livros do acervo institucional, acabam afastando o livro literário dos planejamentos docentes. Ao falarmos da necessidade de um planejamento e de um professor que medeie, aproxime e traga às crianças a proximidade com a literatura nas instituições de Educação Infantil, falamos da viabilização de leitura e de acesso aos livros literários. Professores que entendam a importância da relação das crianças com a literatura ao desenvolvimento da capacidade de criação e imaginação. Doutro modo, os livros permanecerão nas caixas, nos armários, nas secretarias. Ao cumprir seu papel de mediador, com o apoio da literatura e ao planejar e avaliar seu dia a dia, o professor possibilita à criança a ampliação de saberes, conhecimentos, discussões, vivências e experiências.

Convém ressaltar que livros literários, de qualidade reconhecida, não foram entregues e distribuídos por uma política pública nacional para ficar nas caixas. Livros precisam circular, precisam andar pelas mãos, precisam ampliar olhares, precisam gerar questionamentos, conversas, indagações. Livros, tais quais os que foram distribuídos pelo PNBE, que foram cuidadosamente selecionados e avaliados devem ser referência para as leituras realizadas às crianças e pelas crianças. Histórias que precisam ser contadas, lidas, narradas diariamente, tal qual aponta a dissertação de Furtado (2016).

Com os descritores associados Projeto Político-Pedagógico e Educação Infantil, encontramos um total de 90 trabalhos, que foram defendidos entre os anos de 2000 e 2016 , e estão apresentados no Quadro 5, a seguir.

Quadro 5 - Trabalhos encontrados na BDTD com os descritores associados Projeto Político-Pedagógico e Educação Infantil

\begin{tabular}{|l|r|r|r|}
\hline & Total & \multicolumn{1}{|c|}{ Dissertações } & \multicolumn{1}{|c|}{ Teses } \\
\hline Quantidade de trabalhos & 90 & 67 & 23 \\
\hline Trabalhos filtrados por assunto & 22 & 18 & 4 \\
\hline
\end{tabular}

Fonte: Elaborado pelas pesquisadoras.

Aos 90 trabalhos, aplicamos o filtro assunto disponibilizado na plataforma e foram selecionados 22 trabalhos relacionados ao assunto "Educação Infantil", em suas três possibilidades de escrita: Educação Infantil - sete trabalhos; educação infantil - oito trabalhos; e Educação infantil - 17 trabalhos, sendo que, realizada a leitura dos títulos e autores, percebemos que não houve repetição de trabalho nos filtros. 
Nesses 22 trabalhos realizamos a leitura dos resumos e das palavras-chave e selecionamos, para leitura na íntegra, três trabalhos em que o resumo indicava uma aproximação ao que buscamos na presente pesquisa. Os três trabalhos são da área da Educação, sendo duas dissertações e uma tese. No Quadro 6, detalhamos as informações sobre eles.

Quadro 6 - Tese e Dissertações selecionadas na BDTD com os descritores associados Projeto Político-Pedagógico e Educação Infantil

\begin{tabular}{|c|c|c|c|c|c|c|}
\hline Tipo & Ano & Local & Autor & Orientador & Título & Palavras-chave \\
\hline 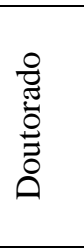 & $\overline{\widetilde{N}}$ & 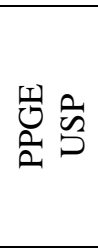 & $\begin{array}{l}\text { Amanda } \\
\text { Cristina } \\
\text { Teagno } \\
\text { Lopes } \\
\text { Marques }\end{array}$ & $\begin{array}{l}\text { Maria } \\
\text { Isabel de } \\
\text { Almeida }\end{array}$ & $\begin{array}{l}\text { A construção de práticas de } \\
\text { registro e documentação no } \\
\text { cotidiano do trabalho } \\
\text { pedagógico da Educação } \\
\text { infantil }\end{array}$ & $\begin{array}{l}\text { Educação infantil, } \\
\text { documentação pedagógica, } \\
\text { práticas pedagógicas na } \\
\text { educação infantil, projeto } \\
\text { político-pedagógico, } \\
\text { registro de práticas. }\end{array}$ \\
\hline 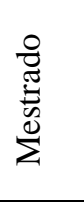 & $\stackrel{m}{\stackrel{n}{\sigma}}$ & 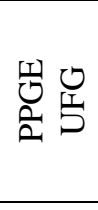 & $\begin{array}{l}\text { Fabiana } \\
\text { Soares } \\
\text { Pimentel }\end{array}$ & $\begin{array}{l}\text { Altina } \\
\text { Abadia da } \\
\text { Silva }\end{array}$ & $\begin{array}{l}\text { Infâncias e direitos das } \\
\text { crianças na educação } \\
\text { infantil: uma análise a partir } \\
\text { do projeto político- } \\
\text { pedagógico }\end{array}$ & $\begin{array}{l}\text { Infância, educação infantil, } \\
\text { projeto político- } \\
\text { pedagógico, direitos das } \\
\text { crianças. }\end{array}$ \\
\hline 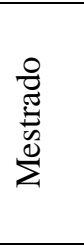 & $\frac{n}{\tilde{d}}$ & 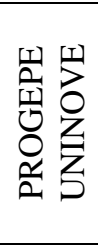 & $\begin{array}{l}\text { Ana } \\
\text { Luiza da } \\
\text { Silva } \\
\text { Vieira }\end{array}$ & $\begin{array}{l}\text { Roberta } \\
\text { Stangherli } \\
\mathrm{m}\end{array}$ & $\begin{array}{l}\text { Projeto político-pedagógico } \\
\text { na creche: participação e } \\
\text { protagonismo da equipe de } \\
\text { funcionárias (os) de uma } \\
\text { unidade da rede municipal } \\
\text { de Santo André. }\end{array}$ & $\begin{array}{l}\text { Creche, educação infantil, } \\
\text { gestão democrática, } \\
\text { participação, projeto } \\
\text { político-pedagógico. }\end{array}$ \\
\hline
\end{tabular}

Fonte: Elaborado pelas pesquisadoras.

A seguir, passamos a apresentação mais detalhada das pesquisas selecionadas anteriormente, tendo como referência as leituras realizadas.

Marques (2011), em sua tese, estuda o processo de documentação realizado em quatro instituições de Educação Infantil, três em São Paulo e uma na Itália, por meio de estudo de caso, em cada uma das instituições, contando com observação participante, pesquisa de documentação e entrevistas. A autora relata a importância do registro como documentação, não só do professor, mas da instituição como um todo e das famílias e crianças, e dialoga com Madalena Freire, Zabalza, Sá-Chaves e Cecília Warschauer acerca do registro como marca. Aponta que diferentes registros compõem a documentação dessas instituições, como projetos de grupo, planejamento da equipe gestora, currículo, diários, vídeos, fotos, relatos, caderno de registro, portfólios; e ressalta a documentação, na fala de adultos e crianças, como tendo a função de comunicação, memória, conhecimento, compartilhamento, visibilidade. Nas Escolas Municipais de Educação Infantil (EMEIs) pesquisadas em São Paulo, é indicada a necessidade de superação do medo da escrita. Relata os projetos coletivos de grupos e seus respectivos registros, destaca a formação em serviço e registra a grande procura por vagas e o atendimento em três turnos em salas com até 35 crianças. A 
autora finaliza seu estudo afirmando que crianças e adultos registram e documentam suas ações, e essas ações dão visibilidade ao PPP das instituições, destacando, ainda, o registro como reconhecimento, avaliação e possibilidade de mudança.

Pimentel (2013), em sua dissertação, apresenta uma retomada histórica dos conceitos de infância e criança e caracteriza a história da Educação Infantil nas legislações brasileiras. Investiga a relação e articulação existente nas práticas educativas vivenciadas em duas instituições de Educação Infantil do município de Goiânia e a escrita de seus respectivos PPPs, onde, com observações, registros, entrevistas e leituras de documentos, explicita a real necessidade de luta para que os direitos das crianças possam ser efetivados e garantidos de fato e não somente em leis. Direitos que possam ser efetivados e vivenciados. Alerta que a participação dos pais na elaboração do PPP está no encaminhamento dos questionários respondidos e na sua presença em reuniões e eventos, bem como reforça que a organização dos tempos e horários das instituições está vinculada ao tempo dos adultos e não das crianças.

Na dissertação de Vieira (2015), realizada enquanto participante da pesquisa, pois era gestora/diretora da instituição, é retratada a importância da gestão democrática para a efetivação da participação de diferentes vozes no PPP da unidade. A autora utilizou como fontes documentais os documentos mais antigos da instituição pesquisada e suas avaliações, documentos do Ministério de Educação e Cultura (MEC) e da Secretaria Municipal de Educação de Santo André (SP), bem como fez observações e registros de 11 rodas de conversas com funcionários. A pesquisa realizada numa creche pública envolveu diferentes profissionais na elaboração do PPP, trazendo para a unidade a cultura da participação, da valorização e do protagonismo. Como conclusão, é apontada a ausência da participação das famílias no documento, considerando-a uma meta a ser alcançada.

Com base na leitura dos três trabalhos com os descritores associados, Projeto PolíticoPedagógico e Educação Infantil, constatamos a importância do registro e da documentação nas instituições, seja como forma de memória, de afirmação dos caminhos metodológicos, de conhecimento acerca das especificidades do trabalho realizado por diferentes grupos, de comunicação entre diferentes atores do processo local ou entre instituições, onde os processos e as diferentes experiências são ressaltados e partilhados. Percebemos que o PPP é um documento dinâmico, vivo, porém, muitas vezes, não expressa o que de fato acontece no cotidiano do trabalho docente, por não ser atualizado constantemente em seus experimentos e registros.

$\mathrm{Na}$ leitura das pesquisas selecionadas, há a falta de dados que fundamentem o processo de construção dos PPPs, que demarquem o documento como parte de uma história, como um documento elaborado coletivamente, que conta com a participação dos diferentes sujeitos/indivíduos do processo educativo e pedagógico que ocorre com e entre as crianças nas instituições. Notamos que a não participação diversas vezes aparece mascarada por respostas a questionários e compilação de dados referentes à situação socioeconômica das famílias, sendo que estas de fato e de direito pouco participam.

Em nenhum dos trabalhos houve menção ao processo de aproximação das crianças com a literatura, ou a projetos de grupos ou coletivos, referentes à nossa questão de 
pesquisa, mas a intenção com o uso dos descritores era, também, perceber como se encontra o estudo e o processo de elaboração desse documento nas instituições de Educação Infantil. Um documento que, ao se propor coletivo, apresenta uma história e uma proposta de trabalho, definida através da intencionalidade da ação educativa realizada junto às crianças.

Com os descritores associados Projeto Político-Pedagógico e Literatura Infantil, encontramos um total de oito trabalhos, que foram defendidos entre os anos de 2003 e 2016, e estão apresentados no Quadro 7, que segue.

Quadro 7 - Trabalhos encontrados na BDTD com os descritores associados Projeto Político-Pedagógico e Literatura Infantil

\begin{tabular}{|l|r|r|r|}
\hline & \multicolumn{1}{|c|}{ Total } & \multicolumn{1}{|c|}{ Dissertações } & Teses \\
\hline Quantidade de trabalhos & 8 & 6 & 2 \\
\hline Trabalhos filtrados por título & 2 & 2 & 0 \\
\hline
\end{tabular}

Fonte: Elaborado pelas pesquisadoras.

Realizada a leitura dos títulos, percebemos que seis trabalhos eram direcionados à pesquisa com o Ensino Fundamental ou a áreas específicas do conhecimento. Selecionamos para leitura dos resumos e palavras-chave duas dissertações, porém, tratavam de temática específica da educação física e de políticas para o ensino fundamental, não sendo, assim, escolhidas para leitura completa.

Com os descritores associados Projeto Político-Pedagógico, Literatura Infantil e Educação Infantil foram encontrados cinco trabalhos, defendidos entre os anos de 2003 e 2016, que são apresentados Quadro 8.

Quadro 8 - Trabalhos encontrados na BDTD com os descritores associados Projeto Político-Pedagógico, Literatura Infantil e Educação Infantil

\begin{tabular}{|l|r|r|r|}
\hline & Total & \multicolumn{1}{|c|}{ Dissertações } & Teses \\
\hline Quantidade de trabalhos & 5 & 4 & 1 \\
\hline Trabalhos filtrados por título & 2 & 2 & 0 \\
\hline
\end{tabular}

Fonte: Elaborado pelas pesquisadoras.

A leitura dos títulos evidenciou que se tratavam dos mesmos trabalhos elencados nos procedimentos de pesquisa anteriores e, portanto, já haviam sido considerados nos itens citados no decorrer da pesquisa. Dentre os trabalhos selecionados na BDTD, realizamos a leitura de uma tese e sete dissertações, que, de algum modo, traziam elementos que dialogavam para a construção teórica do estudo que propúnhamos realizar. 


\section{A pesquisa no Portal de Periódicos da Capes}

O segundo banco de dados em que realizamos a pesquisa foi o Portal de Periódicos da Coordenação de Aperfeiçoamento de Pessoal de Nível Superior (Capes), o qual mantém assinatura com um número considerável de revistas/publicações classificadas pelo programa Qualis em nível A ou B, e que disponibiliza acesso gratuito a textos completos dessas publicações, em nível nacional e internacional.

A plataforma de pesquisa do Portal identificou um total de 1842 artigos relacionados ao descritor Educação Infantil, 1798 ao descritor Literatura Infantil e 282 ao descritor Projeto Político-Pedagógico, números já apresentados no Quadro 1 desta pesquisa. Devido à grande quantidade de trabalhos relacionada aos descritores, optamos por utilizar a pesquisa com os descritores associados. Dentre as possibilidades de textos existentes no portal (artigos, recursos textuais, dissertações, teses, livros, resenhas, atas e outros), selecionamos os seguintes filtros disponibilizados: idioma - português, e tipo de recurso artigos.

No Quadro 9, apresentamos a quantidade de trabalhos, escritos sob a forma de artigos, encontrados no Portal, com os descritores associados.

Quadro 9 - Artigos em língua portuguesa encontrados no Portal de Periódicos da Capes com os descritores associados Literatura Infantil, Projeto Político-Pedagógico e Educação Infantil

\begin{tabular}{|l|r|r|}
\hline \multicolumn{1}{|c|}{ Descritor } & Número de artigos & $\begin{array}{c}\text { Artigos Filtrados no } \\
\text { Portal }\end{array}$ \\
\hline Literatura Infantil e Educação Infantil & 193 & 113 \\
\hline Literatura Infantil e Projeto Político-Pedagógico & 83 & 22 \\
\hline $\begin{array}{l}\text { Literatura Infantil, Projeto Político-Pedagógico e } \\
\text { Educação Infantil }\end{array}$ & 82 & 21 \\
\hline Projeto Político-Pedagógico e Educação Infantil & 8 & 7 \\
\hline
\end{tabular}

Fonte: Elaborado pelas pesquisadoras.

Com os descritores associados Literatura Infantil e Educação Infantil, e depois de aplicados dois filtros disponibilizados no Portal, idioma português e tipo de recurso artigo, ficamos com um total de 113 trabalhos. Realizamos a leitura dos títulos dos 113 artigos e identificamos que a grande maioria não dialogava com a presente investigação, pois suas temáticas de pesquisa eram relacionadas à saúde, inclusão, educação física, educação indígena, literatura como disciplina escolar, educação alimentar, estudo de autores e obras específicas, Ensino Fundamental, entre outros.

Fizemos a leitura dos resumos de 24 artigos que não explicitavam no título a especificidade do trabalho, ou pareciam indicar uma possível aproximação com a discussão que buscávamos. A partir disso, constatamos que muitos dos artigos tratavam da literatura no ensino fundamental ou no ensino médio, analisavam obras ou gêneros específicos de literatura ou se relacionavam com o estudo de outras mídias. Desse modo, selecionamos seis artigos para leitura na íntegra que associavam a Literatura Infantil ao trabalho realizado 
na Educação Infantil, sendo que, cada um a seu modo, traz o diálogo da Literatura Infantil no espaço da Educação Infantil.

O artigo "Educação infantil: literatura como espaço de fruição", de Maraísa Mendes da Costa, Flávia Brocchetto Ramos e Neiva Senaide Petry Panozzo (2008), publicado na revista Signo, analisa o lugar da literatura, da mediação e de estratégias de aproximação das crianças aos livros em salas de aula e em bibliotecas. Apresenta um histórico da literatura destinada ao público infantil, datada do século XVIII, e ressalta a diferenciação entre livros pedagógicos e livros artísticos. Destaca a importância do trabalho docente na mediação dos processos de leitura das crianças, enfatiza o processo gradual de leitura autônoma das crianças e o prazer propiciado pela leitura e descreve o trabalho com uma obra de literatura infantil específica, vivenciado por suas qualidades estéticas, simbólicas, criativas.

Em "Contação de histórias: uma análise da escolha de histórias em um recorte de experiências gaúchas", disponibilizado na revista Conjectura: filosofia e educação, Edgar Roberto Kirchof e Rosa Maria Hessel Silveira (2009) destacam a "pedagogização" das horas do conto na Educação Infantil e Ensino Fundamental, em instituições gaúchas. A escrita faz-se apoiada nos relatos de alunas da pedagogia, entre os anos de 2005 e 2007, em atividades de observação e entrevista, junto a professores dessas duas etapas da educação básica. Na composição do enredo textual são pontuados critérios de escolhas dos livros, caráter das conversas realizadas após os contos e as possíveis relações dos contos a um projeto da sala, indicando seu caráter marcadamente pedagógico. Os autores enfatizam que, apesar de expressar um número pequeno de ocorrências, há relato de práticas com outros discursos e alternativas, alinhados a uma fruição estética e literária aos pequenos leitores.

$\mathrm{O}$ artigo "A literatura como brinquedo e a formação da criança leitora", de Catarina Xavier Gonçalves Martins (2012), da Revista Eletrônica de Educação, aponta a importância da utilização e incentivo à realização da leitura literária tanto na Educação Infantil quanto no Ensino Fundamental. Evidencia o livro de literatura infantil como um recurso pedagógico e traça a relação deste com a possibilidade da brincadeira. Ressalta a ausência da leitura enquanto possibilidade de brincadeira no cotidiano de educação de muitas crianças, bem como a carência de acesso de muitos aos livros de literatura infantil. Cita alguns programas governamentais de incentivo à leitura e destaca o acesso à leitura como um bem cultural.

$\mathrm{O}$ artigo "A importância da literatura infantil para a aprendizagem significativa da criança", publicado na revista Letrando, Márcia Cecília de Oliveira Carregosa (2012) busca explicitar a significação da literatura infantil como Arte e Literatura, sem diminutivos. Evidencia a contribuição desta ao desenvolvimento e à aprendizagem da criança, revelando as potencialidades educativas do texto literário, através do sentido estabelecido entre o leitor e a obra. Entre contos de fadas e poesias, a autora avaliou as possibilidades do ato de aprender e ressaltou que no brincar há o chamado ao gosto pela leitura, enfatizando a aproximação dos atos de brincar e de ler. Trouxe para discussão os temas transversais, a Lei $n^{\circ} 10.639 / 2003$ (BRASIL, 2003) e a utilização da literatura como possibilidade de trabalho com diferentes conteúdos junto às crianças. Discute a relação entre alfabetização e leitura e salienta a mediação como componente do processo de aprendizagem. 
Em "Políticas públicas de leitura em Portugal e Brasil: novos caminhos, velhos problemas", a pesquisadora portuguesa Angela Balça e brasileira Renata Junqueira de Souza (2012), em artigo publicado no periódico Educação, destacam a ação de diferentes políticas públicas de leitura que vêm sendo investidas nos dois países, aliadas a um problema comum: o baixo acesso da população de modo geral aos livros e aos livros literários. As autoras relacionam as políticas à necessária prática continuada de formação docente, pois a simples oferta/entrega do produto não proporciona o acesso requerido pelo programa. Evidenciam dados de participação desses dois países em exames internacionais e nacionais e centram suas convicções na promoção de programas de leitura, na formação continuada e em serviço, na oferta dos livros às crianças. Evidenciam a necessidade urgente de que os mediadores de leitura, de fato leiam e estimulem a leitura!

Em "Educação infantil e literatura: um direito a sonhar, ampliar e construir repertório", publicado na revista Conjectura: filosofia e educação, os autores Renata Junqueira de Souza e Irando Alves Martins (2015) discutem o direito do acesso das crianças à literatura, afirmando-o como direito fundamental de todas as pessoas. Falam da importância de se assegurar o acesso ao livro literário e, também, do direito de escolha, para além daquilo que é oferecido. Destacam a importância do planejamento pedagógico com relação à leitura de textos literários às crianças, chamando atenção ao papel mediador do professor. Há no artigo referência às políticas públicas nacionais de fomento e incentivo à presença do livro de literatura nos espaços da Educação Infantil. Além disso, apresentam o livro como patrimônio cultural e ressaltam a leitura como possibilidade de novas aprendizagens.

Os artigos selecionados destacam a leitura como um aspecto muito importante do trabalho realizado na Educação Infantil, enfatizando que precisa ser mais incentivada e valorizada, tanto na Educação Infantil como no Ensino Fundamental. Apontam o acesso à leitura como parte da tarefa da escola/instituição educativa e revelam a importância dos programas de fomento à leitura e de incentivo ao acesso aos livros pelas crianças. Acessibilidade de crianças e adultos, onde ambos possam ler, aprender, desenvolver-se, ampliando seu conhecimento e estabelecendo diálogos com a linguagem artística e também com a linguagem pedagógica. Ressaltam também a importância do papel do professor como mediador e incentivador da leitura e da formação do gosto pela leitura entre as crianças, realçando a importância da formação qualificada para esse profissional, do planejamento docente, do incentivo aos processos de autonomia na leitura.

Com a utilização dos descritores associados Projeto Político-Pedagógico e Literatura Infantil, chegamos a 83 publicações, e com os descritores associados Projeto PolíticoPedagógico, Educação Infantil e Literatura Infantil, 82 publicações. A essas publicações aplicamos dois filtros disponibilizados na plataforma, selecionando somente artigos escritos em língua portuguesa. Nesse refinamento, a plataforma apresentou 22 artigos à primeira pesquisa, e 21 artigos à segunda. Realizada a leitura dos títulos, constatamos que se tratavam dos mesmos trabalhos.

A partir da leitura dos títulos, identificamos artigos relacionados à educação alimentar, educação inclusiva, educação indígena, educação bilíngue, formação de nutricionistas, de contadores, artigos da área da saúde, das escolas técnicas, de estudos feministas, de 
questões de sexualidade, de gênero, de sustentabilidade, temáticas distantes de nosso interesse específico nesta investigação. Realizamos a leitura de cinco resumos, cujos títulos descreviam trabalhos com formação docente; no entanto, vimos tratar-se de perspectivas de educação superior e seu currículo, o ensino de uma disciplina específica de um curso superior, a avaliação da educação superior e a maturidade da escolha profissional. Assim, apenas um artigo foi selecionado para leitura na íntegra. Realizada a leitura, percebemos que e analisava o crescimento da oferta de Educação Infantil em razão da aprovação de um fundo nacional com direcionamento de ação também a essa etapa educacional. Portanto, não se relacionava à temática da pesquisa em pauta.

Com os descritores associados Projeto Político-Pedagógico e Educação Infantil, chegamos a um total de oito trabalhos na plataforma, e selecionamos, a partir da leitura dos resumos e das palavras-chave, um para leitura na íntegra, a saber, "A construção de uma alternativa curricular para a pré-escola: a experiência do NEI Canto da Lagoa", de Ana Cristina Coll Delgado (1998). O artigo retrata o processo de discussão e construção de um PPP na Educação Infantil. Publicado na revista Educação e Sociedade, o texto realiza a apresentação da comunidade e as relações entre os profissionais, entre profissionais e a comunidade, e com as crianças de dois grupos da instituição. Aponta a efetiva participação dos familiares nas propostas pedagógicas e discute acerca da não percepção da cultura infantil no fazer pedagógico.

Devido ao número reduzido de trabalhos relacionados ao descritor Projeto PolíticoPedagógico, realizamos uma nova pesquisa no Portal a partir dos 282 trabalhos primeiramente selecionados com o descritor isolado. Desse modo, consideramos somente artigos no idioma português e obtivemos 186 trabalhos relacionados. Utilizamos outro filtro, nominado no Portal como tópico, e elegemos o tópico projeto político-pedagógico, o qual apresentou 25 artigos. Dentre eles, realizamos a leitura dos títulos e constatamos que alguns tratavam dos seguintes temas: currículos de outras áreas do ensino superior, como medicina, enfermagem, contabilidade, nutrição, psicologia, educação física, física, dança; outros de programas específicos realizados com jovens, estudantes de escolas técnicas, alunos do Ensino Fundamental; ou ainda de temas específicos como diversidade e inclusão.

Realizamos a leitura de nove resumos, cujos títulos não especificavam ou não detalhavam o que de fato tratavam, mas que pareciam se aproximar das discussões que buscávamos. Dentre as leituras dos resumos, verificamos que alguns tratavam de temáticas específicas e foram desconsiderados. Houve a repetição do artigo de Delgado (1998), já citado e comentado. Assim, selecionamos dois artigos para leitura na íntegra.

$\mathrm{O}$ artigo "A significação do projeto político-pedagógico: um olhar avaliativo", de Samara Wanderley Xavier Barbosa (2012), publicado na revista Espaço do Currículo, trata dos discursos sobre a construção do PPP de uma escola pública, avaliando-os como espaços de negociação e disputas. Cita documentos que revelam normas, diretrizes e decisões políticas do contexto educacional local e nacional, bem como destaca alguns autores que tratam do PPP, como Rossi, com os "PPPs reguladores e os emancipadores", e Veiga, com o PPP como "organizador do trabalho da escola". Trata também do processo de gestão democrática da escola. 
Em "Projeto político-pedagógico: construção de política curricular no contexto da prática", publicado no periódico Terci, Rosalva de Cássia Rita Drummond e Danielle Gomes Rodrigues (2014) discutem os silenciamentos, consensos e exclusões na escrita do PPP do Colégio de Aplicação, do Instituto Superior do Estado do Rio de Janeiro (ISERJ), da Educação Infantil ao Ensino Superior. Destacam o planejamento coletivo como modo de mobilização, integração e participação, destacando a legitimidade de seus apontamentos, da sistemática de avaliação, dos processos de discussão e produção do currículo.

A pesquisa no Portal da Capes favoreceu o embasamento teórico deste estudo com nove artigos que foram lidos na íntegra. Dentre os artigos selecionados para leitura, seja de seus resumos ou aqueles lidos na íntegra, no que se refere ao PPP, constatamos que são atitudes frequentes na elaboração e construção desses os jogos de força e interesses, muitas vezes com participação mínima dos familiares ou dos próprios professores/funcionários, ou ainda elaborados pelas secretarias das instituições e simplesmente apresentados aos profissionais e familiares.

Verificamos nas leituras que nem sempre o PPP é apresentado e disponibilizado a todos os partícipes da instituição, constituindo-se, em muitos casos, um "documento de gaveta". Os artigos selecionados evidenciam a preocupação de que, em um processo de gestão democrática, conste na escrita do documento o conhecimento das legislações que referenciam o trabalho realizado na Educação Infantil, como se a legislação fosse de amplo conhecimento da comunidade educativa em geral, e como se o fato de tê-los destacado garantisse a efetivação de uma prática diferenciada.

E entre a escrita, a legitimação e a utilização do documento, como referência a um planejamento coletivo, que indicam a direção e a caminhada na construção de um trabalho, há muito a ser escrito, formulado e sistematizado, para que, de fato, o documento materializado na escrita do PPP se torne fonte de consulta e referência a todos os que chegam à instituição, e consiga apresentar o trabalho realizado nas mesmas.

\section{A pesquisa no Scientific Eletronic Library Online (SciELO)}

O terceiro banco de dados em que realizamos a pesquisa foi no Scientific Eletronic Library Online (SciELO), uma biblioteca eletrônica que mantém uma coleção de periódicos científicos brasileiros e internacionais, e que disponibiliza acesso gratuito a textos completos destas coleções.

A plataforma de pesquisa do SciELO identificou 1050 artigos relacionados ao descritor Educação Infantil, 657 ao descritor Literatura Infantil e 137 ao descritor Projeto Políticopedagógico, números já apresentados no Quadro 1 desta pesquisa.

Em virtude da grande quantidade de trabalhos relacionados às temáticas apresentadas, realizamos a pesquisa também com os descritores associados. Dessa forma, houve uma redução no número de trabalhos, que são apresentados no Quadro 10. 
Quadro 10 - Trabalhos disponibilizados no SciELO, conforme os descritores associados: Projeto Político-pedagógico, Literatura Infantil e Educação Infantil

\begin{tabular}{|l|r|}
\hline \multicolumn{1}{|c|}{ Descritores associados: } & \multicolumn{1}{c|}{ Artigos } \\
\hline Literatura Infantil e Educação Infantil & 98 \\
\hline Literatura Infantil e Projeto Político-pedagógico & - \\
\hline Projeto Político-pedagógico e Educação Infantil & 4 \\
\hline Projeto Político-pedagógico, Literatura Infantil e Educação Infantil & - \\
\hline
\end{tabular}

Fonte: Elaborado pelas pesquisadoras.

Com os descritores Literatura Infantil e Educação Infantil utilizados de forma associada, foram selecionados 98 trabalhos. Aplicamos alguns filtros disponibilizados para a pesquisa, dentre eles: coleções - brasileiras; idioma - português; tipo de literatura artigos; áreas temáticas - ciências humanas, ciências sociais, linguística, letras e arte. Desse modo, conseguimos estabelecer um número de 52 artigos para leitura de seus títulos. Encontramos muitos artigos que tratavam do Ensino Fundamental, além de outros com temáticas específicas, como desenho infantil, análise de obras e autores, deficiência, folclore, classes hospitalares, publicidades, poesias, violência, gênero, revistas, vagas, personagens negros, trabalho infantil, assim excluídos por não estarem em conformidade com nossa busca.

Realizada nova leitura dos títulos, ficamos com nove artigos, os quais lemos os resumos e palavras-chave. Desses, quatro tratavam do Ensino Fundamental; um já fora selecionado no portal anterior; outro tratava da relação entre linguagem visual e verbal na constituição escrita de um livro. Assim, ficamos com três artigos para a realização da leitura na íntegra, cujos resumos são apresentados a seguir.

Em "Histórias infantis e aquisição da escrita", Vera Lúcia Blanc Simões (2000), na revista São Paulo em Perspectiva, cita estudos atuais que indicam a importância exercida pela Educação Infantil na aprendizagem das crianças. Assinala que o acesso e o manuseio de materiais diferenciados e a organização de ambientes propícios à leitura permite, desde muito cedo, a construção de significados acerca do papel e das funções da leitura e da escrita. Destaca o impacto, a fascinação e as possibilidades criativas que as histórias exercem sobre as crianças, e ressalta as diferentes maneiras de contar histórias, trazendo-as como atividade diária a ser incentivada, mediada, apresentada às crianças. Ressalta também o incentivo ao desenho, a oralidade e a expressão, através de recontos, dramatizações, conversas, produções de textos coletivos, onde as crianças se envolvam com o enredo e possam criar novas histórias e produzam suas escritas, valorizando e percebendo a importância de diferentes linguagens.

No artigo "Biblioterapia para crianças em idade pré-escolar: estudo de caso", Eliane R. de Oliveira Lucas, Clarice Fortkamp Caldin e Patrícia V. Pinheiro da Silva (2006) relatam uma experiência realizada em 13 encontros com 22 crianças da Educação Infantil, de período integral. Publicado na revista Perspectivas em Ciências da Informação, as autoras apresentam a necessidade de parceria entre os bibliotecários e professores na formação de 
leitores, justificam o pouco acesso das crianças aos livros ao valor desses no mercado. Apontam ainda uma prática comum nas escolas, em que os livros ficam longe do acesso das crianças para não serem estragados. Citam várias possibilidades de trabalho com a leitura, os locais onde a leitura se faz presente, as funções que pode desempenhar e relatam os encontros com as crianças, as histórias contadas, as reações, as propostas apresentadas, as participações das crianças e a presença do elemento lúdico nas situações relatadas.

No artigo "Na história do ensino da literatura no Brasil: problemas e possibilidades para o século XXI", Maria do Rosário Longo Mortatti (2014), no periódico Educar em Revista, relata a trajetória histórica de diferentes momentos de ensino da literatura no Brasil e as relações entre literatura, educação e ensino na formação de professores. Entre a escolarização da leitura literária nos livros didáticos e a opção da leitura literária do livro na escola para formar leitores, a autora aponta que o direito à literatura diz respeito ao direito à leitura literária de bons textos literários. Empreende esforços para reafirmar que cabe ao professor "ler e ensinar seus alunos a ler bons textos literários". Ressalta a importância da leitura literária na escola, na formação de professores, no desenvolvimento do gosto, da estética e da apropriação do patrimônio nacional.

Esses três artigos, no seu conjunto, incentivam a prática e a aproximação de leitura e da escrita desde cedo com as crianças. Destacam os benefícios do acesso das crianças aos livros e as mais diferentes linguagens, referendando que, com esse acesso, as crianças têm a possibilidade de ampliação de conhecimentos, de culturas, de enredos. Discorrem sobre a importância da organização de ambientes propícios à aprendizagem e assinalam a presença de elementos lúdicos nos momentos de leitura como necessários a uma possível formação do gosto pela leitura. Ludicidade essa que favorece a imaginação, a criação, a fantasia, a invenção, e que, estão presentes em bons textos literários, que precisam estar ao acesso e ao conhecimento das crianças. Em virtude disso, os autores ressaltam a importância da seleção de bons livros à leitura com as crianças.

Com os descritores associados Projeto Político-pedagógico e Educação Infantil, a plataforma SciELO apresentou quatro artigos. Dentre eles, verificamos, pelo título, que um tratava da alimentação escolar, outro do projeto de formação dos cursos de pedagogia e dois discutiam a atuação do psicólogo escolar na Educação Infantil. Assim, nenhum deles estabelecia relação direta com a temática da presente investigação. A pesquisa realizada no Portal da SciELO propiciou a seleção de três artigos que foram lidos na integra e que compuseram parte do cabedal de conhecimento à temática investigada.

\section{Das conclusões possíveis}

Considerando a leitura das produções presentes no levantamento realizado nos diferentes bancos de dados, com os descritores associados: Educação Infantil, Literatura Infantil e Projeto Político-pedagógico, constatamos que a relação entre a Literatura Infantil, a Educação Infantil e o Projeto Político-pedagógico (PPP) não está no foco das pesquisas. Escreve-se e pesquisa-se sobre a Educação Infantil, sobre a Literatura Infantil, 
sobre a Literatura Infantil na Educação Infantil, mas não sobre a ação e o registro desse trabalho nos documentos norteadores da ação educativa das instituições, ou seja, não há atenção à presença da Literatura nos PPPs das instituições de Educação Infantil.

A produção acadêmica e os artigos selecionados na pesquisa que tratam dos PPPs destacam discussões acerca da participação, da gestão democrática, da utilização de documentos e normativas que respaldam o funcionamento da instituição, com vistas à construção de uma história, uma memória. Histórias de adultos, de estudos, de construção de documentos, mas não histórias de crianças, de sua participação dentro das instituições, ou de ações a elas direcionadas. A literatura, o planejamento, as ações educativas, realizadas cotidianamente com as crianças não ganham visibilidade nas pesquisas que referendam ou citam a construção dos PPPs. Sendo o PPP destacado em alguns trabalhos como um documento que orienta as ações da docência, da gestão e da administração, bem como as ações coletivas da instituição, consideramos viável e necessário focar nossa atenção nesse documento, no intuito de perceber a sua intencionalidade e ação no trabalho realizado cotidianamente nas instituições educativas.

Ao detalhar o estado do conhecimento realizado, esperamos ter contribuído com outros pesquisadores, tanto do ponto de vista metodológico da realização do próprio levantamento, quanto do conteúdo tema da nossa investigação e as possíveis perguntas que se colocam para novas investigações.

Compreendemos, com a realização do Estado do Conhecimento, a relevância e a necessidade de investigar se o direito da criança à educação e ao acesso à cultura, a partir da leitura e das diferentes possibilidades de ampliação de repertórios que a literatura propicia, está presente no Projeto Político-pedagógico (PPP) das instituições de Educação Infantil públicas de uma rede municipal no estado de Santa Catarina. E deste modo poder compor um quadro de pesquisas em que o PPP possa aparecer para além do seu estado de documento formal e constar como documento vivo da dinâmica e ações realizadas ou propostas de realização às crianças que estão nesta etapa educativa.

\section{Referências}

ALBUQUERQUE, Cinthia Silva de. Os acervos, os espaços e os projetos de leitura em instituições públicas de educação infantil do Recife. 2013. Dissertação (Mestrado em Educação) - Universidade Federal de Pernambuco, Recife, 2013. Disponível em: <http://repositorio.ufpe.br/handle/123456789/12856>.

ANDRADE, Lizbeth Oliveira de. Desenvolvimento da memória em crianças pré-escolares por meio de atividades literárias: contribuições da teoria histórico-cultural. 2013. Dissertação (Mestrado em Educação) - Universidade Estadual Paulista, Marília, SP, 2013. Disponível em: <http://repositorio.unesp.br/bitstream/handle/11449/137813/andrade_lo_me_mar.pdf?sequence=3>.

BALÇA, Angela; SOUZA, Renata Junqueira de. Políticas públicas de leitura em Portugal e Brasil: novos caminhos, velhos problemas. Revista Educação, Porto Alegre, v.35, n. 3, p. 371-379, set./dez., 2012. Disponível em: 〈http://revistaseletronicas.pucrs.br/ojs/index.php/faced/article/viewFile/11771/8394>. 
BARBOSA, Samara Wanderley Xavier. A significação do projeto político-pedagógico: um olhar avaliativo. Espaço do currículo, João Pessoa, v. 4, n. 2, p. 227-239, 2012. Disponível em: <http://periodicos.ufpb.br/ojs/index.php/rec/article/view/12339/7115>.

BORELLA, Thaís. Desenvolvimento da linguagem infantil à luz da teoria histórico-cultural: contribuições de práticas literárias na primeira infância. 2016 Dissertação (Mestrado em Educação) Universidade Estadual Paulista, Presidente Prudente, 2016. Disponível em: $<$ http://repositorio.unesp.br/bitstream/handle/11449/138334/borella_t_me_prud.pdf?sequence=3\&isAllow ed $=\mathrm{y}>$.

BRASIL. Lei $\mathrm{n}^{\circ}$ 10.069, de 9 de janeiro de 2003. Altera a Lei no 9.394, de 20 de dezembro de 1996, que estabelece as diretrizes e bases da educação nacional, para incluir no currículo oficial da Rede de Ensino a obrigatoriedade da temática "História e Cultura Afro-Brasileira", e dá outras providências. Diário Oficial da União, Brasília, 10 jan. 2003.

CARREGOSA, Márcia Cecília de Oliveira. A importância da literatura infantil para a aprendizagem significativa da criança. Revista Letrando, Paripiranga, BA, v. 1, 2012. Disponível em: <http://revistaletrando.com/revista/volume1/15.Marcia.pdf〉.

COSTA, Maraísa Mendes da; RAMOS, Flávia Brocchetto; PANOZZO, Neiva Senaide Petry. Educação infantil: leitura como espaço de fruição. Signo, Santa Cruz do Sul, v. 32, n. 53, p. 128-140, jul. 2007. Disponível em: <https://online.unisc.br/seer/index.php/signo/article/view/82>.

DANNA, Taís. Literatura e imaginação: realidade e possibilidades em um contexto de educação infantil. 2007. Dissertação (Mestrado em Psicologia) - Universidade Federal de Santa Catarina, Florianópolis, 2007. Disponível em: <http://repositorio.ufsc.br/xmlui/handle/123456789/90653>.

DELGADO, Ana Cristina Coll. A construção de uma alternativa curricular para a pré-escola: a experiência do NEI Canto da Lagoa. Educação \& Sociedade, Campinas, SP, v. 19, n. 63, p. 126-152, 1998. Disponível em: <http://www.scielo.br/scielo.php?script=sci_arttext\&pid=S0101-73301998000200008>.

DRUMMOND, Rosalva de Cássia Rita; RODRIGUES, Danielle Gomes. Projeto político-pedagógico: construção de política curricular no contexto da prática. Terci, Rio de Janeiro, v. 3, n. 1, p. 34-46, 2014. Disponível em: <http://www.cnecrj.com.br/ojs/index.php/temiminos/article/view/46>.

FURTADO, Thamirys Frigo. Espaços e tempos coletivos de leitura literária na educação infantil da rede municipal de Florianópolis (SC). 2016. Dissertação (Mestrado em Educação) - Universidade Federal de Santa Catarina, Florianópolis, 2016. Disponível em: $<$ https://repositorio.ufsc.br/xmlui/bitstream/handle/123456789/169071/342148.pdf?sequence=1\&isAllowe $\mathrm{d}=\mathrm{y}>$.

KIRCHOF, Edgar Roberto; SILVEIRA, Rosa Maria Hessel. Contação de histórias: uma análise da escolha de histórias em um recorte de experiências gaúchas. Conjectura: filosofia e educação, Caxias do Sul, RS, v. 14, n. 2, maio/ago. 2009.2 Disponível em: <http://www.ucs.br/etc/revistas/index.php/conjectura/article/view/24>.

LUCAS, Eliane R. de Oliveira; CALDIN, Clarice Fortkamp; SILVA, Patrícia V. Pinheiro da. Biblioterapia para crianças em idade escolas: estudo de caso. Perspectivas em Ciências da Informação, Belo Horizonte, v. 11, n. 3, set./dez. 2006. Disponível em: $<$ http://www.scielo.br/scielo.php?script=sci_arttext\&pid=S1413-99362006000300008\&lang=pt $>$.

MARQUES, Amanda Cristina Teagno Lopes. A construção de práticas de registro e documentação no cotidiano do trabalho pedagógico da Educação infantil. 2011. Tese (Doutorado em Educação) Universidade de São Paulo, São Paulo, 2011. Disponível em: <http://www.teses.usp.br/teses/disponiveis/48/48134/tde-07042011-141501/pt-br.php>.

MARTINS, Catarina Xavier Gonçalves. A literatura como brinquedo e a formação da criança leitora. Revista eletrônica de educação, São Carlos, SP, v. 6, n. 2, p. 468-475, nov. 2012. Disponível em: $<$ http://www.reveduc.ufscar.br/index.php/reveduc/article/view/263/213> 
MORTATTI, Maria do Rosário Longo. Na história do ensino de literatura no Brasil: possibilidades para o século XXI. Educar em Revista, Curitiba, n. 52, abr./jun. 2014. Disponível em: <http://www.scielo.br/scielo.php?script=sci_arttext\&pid=S0104-40602014000200003\&lang=pt>.

PIMENTEL, Fabiana Soares. Infâncias e direitos das crianças na educação infantil: uma análise a partir do projeto político-pedagógico. 2013. Dissertação (Mestrado em Educação) - Universidade Federal de Goiás, Catalão, 2013. Disponível em: <https://repositorio.bc.ufg.br/tede/handle/tede/3393>.

SIMÕES, Vera Lúcia Blanc. Histórias infantis e aquisição da escrita. São Paulo em perspectiva, São Paulo, $\begin{array}{llllll}\text { v.14, } & \text { n. } & 1, & \text { jan./mar. } & 2000 . & \text { Disponível }\end{array}$ <http://www.scielo.br/scielo.php?script=sci_arttext\&pid=S0102-88392000000100004\&lang=pt>.

SOUZA, Renata Junqueira de; MARTINS, Irando Alves. Educação infantil e literatura: um direito a sonhar, ampliar e construir repertório. Conjectura: filosofia e educação, Caxias do Sul, RS, v. 20, n. especial, p. 221-239, 2015. Disponível em: <http://www.ucs.br/etc/revistas/index.php/conjectura/article/view/3660>

VIEIRA, Ana Luiza da Silva. Projeto político-pedagógico na creche: participação e protagonismo da equipe de funcionárias (os) de uma unidade da rede municipal de Santo André. 2015. Dissertação (Mestrado em Educação) - Universidade Nove de Julho, São Paulo, 2015. Disponível em: <https://bibliotecatede.uninove.br/handle/tede/1207>.

\section{Correspondência}

Simoni Conceição Claudino: Prefeitura Municipal de Florianópolis/PPGE UFSC.

E-mail: simoniclaudinoccp@ hotmail.com

Diana Carvalho de Carvalho: Curso de Pedagogia/Psicologia na UFSC.

E-mail: dianacc@terra.com.br

Eliane Santana Dias Debus: Universidade Federal de Santa Catarina.

E-mail: elianedebus@hotmail.com

Texto publicado em Currículo sem Fronteiras com autorização das autoras 